\title{
Penerapan Bahasa Inggris Terintegrasi Dengan Pembelajaran Di TPQ Al-Mataab Desa Tembokrejo - Muncar - Banyuwangi
}

\author{
Roudlotun Nurul Laili ${ }^{1)}$, Muhammad Nashir ${ }^{2)}$ \\ ${ }^{1,2}$ Sekolah Tinggi Ilmu Kesehatan (STIKES) Banyuwangi \\ Email: uutnashir996@gmail.com ${ }^{1)}$, nashirmuhammad123@gmail.com ${ }^{2)}$
}

\begin{abstract}
As one of world languages, English is broadly used in many aspects such as science, business, technology, and education. Thus English is highly necessary to be introduced as soon as possible to the students in order to compete in the globalization era. The purpose of this community service activity is to integrate the English material in the curriculum of TPQ (Al-Qur'an Learning Center), so the students can know earlier about English as a global language. This activity was conducted at TPQ Al-Mataab Tembokrejo - Muncar - Banyuwangi in which the classes were divided into two, they are class A (students aged 7-10) and class B (students aged 11-14). The methods used were drilling, flashcard, and songs in training and giving Basic English materials to the students. Some steps in performing this activity were preparation, conducting pre test to find out the initial of students' English ability, training and teaching, and giving post test to know the progress of the activity. The mean score result of class A showed the enhancement from 43.89 in pre test to 62.41 in post test. While in class B the pre test result was 61.4 and in post test increase into 71.6. It indicated that students are eager and excited in learning English and it is feasible and potential to be integrated in TPQ curriculum.
\end{abstract}

Key Words: English; TPQ (Taman Pendidikan Al-Qur'an); Learning.

\begin{abstract}
Abstrak
Sebagai salah satu bahasa dunia, bahasa Inggris digunakan secara luas dalam banyak aspek seperti ilmu pengetahuan, bisnis, teknologi, dan pendidikan. Sehingga bahasa Inggris sangat diperlukan untuk diperkenalkan sesegera mungkin kepada para siswa agar dapat bersaing di era globalisasi. Tujuan dari kegiatan pengabdian masyarakat ini adalah untuk mengintegrasikan materi bahasa Inggris dalam kurikulum TPQ, sehingga santri dapat mengenal Bahasa Inggris lebih awal sebagai bahasa global. Kegiatan ini dilakukan di TPQ Al-Mataab - Tembokrejo - Muncar - Banyuwangi yang mana kelas di TPQ dibagi menjadi dua, yaitu kelas A (santri berusia 7-10 tahun) dan kelas B (santri berusia 11-14 tahun). Metode yang digunakan adalah drilling, flashcard, dan lagu dalam memberikan pelatihan dan materi Bahasa Inggris Dasar kepada santri. Beberapa langkah dalam pelaksanaan kegiatan ini adalah persiapan, melakukan pretest untuk mengetahui kemampuan awal bahasa Inggris santri, memberikan pelatihan dan pengajaran, dan memberikan post test untuk mengetahui kemajuan hasil kegiatan. Hasil nilai rata-rata kelas A meningkat dari 43,89 pada pretest menjadi 62,41 pada posttest. Sedangkan di kelas $B$ hasil pretest 61,4 dan pada posttest meningkat menjadi 71,6. Ini menunjukkan bahwa santri sangat bersemangat dalam belajar bahasa Inggris dan hal ini sangat bagus dan layak untuk diintegrasikan dengan kurikulum di TPQ.
\end{abstract}

Kata Kunci: Bahasa Inggris; TPQ (Taman Pendidikan Al-Qur'an); Pembelajaran.

\section{PENDAHULUAN}

Bahasa Inggris sebagai bahasa komunikasi Internasional dunia memegang peranan penting di berbagai sektor termasuk sektor pendidikan. Hal ini selaras dengan pernyataan Crystal (2003: 3) bahwa banyak negara - negara di berbagai belahan dunia mempelajari bahasa inggris dan menggunakan bahasa inggris sebagai media untuk berkomunikasi karena kapasitasnya sebagai bahasa global. Saat ini, bahasa Inggris telah digunakan dalam aspek ilmu 
pengetahuan, perdagangan internasional, teknologi, bisnis, dan pendidikan. Jadi sangat logis jika bahasa Inggris digunakan bahasa kedua di banyak negara karena perannya dalam banyak aspek kehidupan manusia. Oleh karena itu, bahasa Inggris harus dipelajari dan dikuasai oleh anak bangsa agar mampu bersaing dengan negara lain di era globalisasi ini.

Di Indonesia selain Pendidikan formal seperti Sekolah Dasar (SD), SMP, dan SMA, juga terdapat pendidikan non formal yaitu pendidikan dan pengetahuan yang didapatkan oleh seseorang diluar pendidikan formal dan pelaksanaannya terstruktur dan terarah. Dalam pendidikan non formal seseorang dapat memperoleh wawasan, ilmu, pelatihan serta bimbingan berdasarkan tingkat usia dan kebutuhan, yang bertujuan untuk mengembangkan keterampilan, kualitas, dan sikap yang memungkinkan baginya menjadi pesertapeserta yang mampu menjadikan mereka efektif dan berdaya guna dalam lingkungannya. (Joesoef, 1992: 50). Contoh pendidikan nonformal antara lain lembaga kursus dan pelatihan, pusat kegiatan belajar masyarakat, majelis ta'lim pengajian, dan TPQ (Taman Pendidikan Al Quran) yang umumnya dilaksanakan di masjid atau musholla.

Tuntutan untuk bisa menghasilkan sumber daya yang berkualitas dan mampu berdaya saing global, juga menstimulasi pendidikan non formal seperti TPQ (Taman Pendidikan Al-Qur'an) untuk menyisipkan bahasa inggris sebagai materi tambahan dalam cakupan kurikulum TPQ karena sejauh ini lembaga TPQ hanya mengajarkan mengaji, membaca Al-Qur'an, dan bahasa Arab. Mengingat pentingnya bahasa Inggris sebagai lingua franca, bahasa penghubung di kancah internasional, maka bahasa Inggris sangat perlu dikenalkan sejak dini kepada para santri yang mayoritas adalah anak - anak berusia sekolah dasar karena merupakan periode sensitif untuk mempelajari bahasa. Bahasa Inggris merupakan bahasa asing di Indonesia dan mungkin bagi beberapa santri inilah pertama kali buat mereka mengenal bahasa Inggris, jadi asumsi bahwa bahasa Inggris itu sulit pasti bermunculan. Oleh sebab itu pengenalan bahasa Inggris bagi santri harus dikemas semenarik mungkin agar siswa tidak bosan dan terus termotivasi untuk belajar bahasa Inggris.

Sejak tahun 2016 TPQ Al-Mataab menginginkan bahasa Inggris menjadi muatan lokal yang terintegrasi dengan pembelajaran di TPQ agar para santri memiliki nilai Plus yaitu selain menimba ilmu agama dan bisa mengaji mereka juga memiliki skill bahasa inggris. Tetapi permasalahan utamanya adalah tidak ada tenaga pengajar di TPQ (ustadz maupun ustadzah) yang kompeten dan mampu mengajarkan bahasa Inggris kepada santrinya, sedangkan untuk mendatangkan tenaga pengajar bahasa Inggris tidak ada sumber dana yang digunakan untuk menggaji tenaga pengajar tersebut karena santri yang mengaji hanya dipungut biaya kecil sekali, itupun untuk membayar iuran listrik bulanan dan kebutuhan ATK (Alat Tulis Kantor) untuk menunjang kegiatan belajar mengajar di TPQ.

TPQ Al-Mataab berlokasi di desa Tembokrejo - Muncar - Banyuwangi yang dipimpin oleh Ustad Muhammad Nur Wahid dan Istrinya Ibu Mutammamah. TPQ ini memfasilitasi masyarakat desa sekitar yang ingin mengenalkan anak anaknya tentang agama dan belajar mengaji. Ada 2 kelas di TPQ Al - Mataab dan waktu pengajarannya dibagi 2 , yaitu sore setelah ashar dan setelah magrib. Setelah ashar untuk santri kelas A (anak usia 7-10 tahun) dengan jumlah 27 orang dan kelas B (anak usia 11-14 tahun) dengan 
DOI: https://doi.org/10.21009/sarwahita.152.02

P-ISSN: 0216-7484

E-ISSN: 2597-8926

jumlah 25 orang, waktu mengajinya setelah magrib.

Berdasarkan permasalah utama yang disampaikan oleh Ketua TPQ AlMataab, maka kami mendedikasikan diri untuk membantu memecahkan masalah tersebut yaitu dengan mengabdikan diri untuk memberikan pelatihan dan pengajaran materi dasar/pengenalan bahasa inggris tanpa membebani biaya apapun terhadap ketua TPQ maupun para santri. Kegiatan ini dilakukan berkolaborasi dengan mahasiswa yang tergabung dalam UKM (Unit Kegiatan Mahasiswa) English club STIKES Banyuwangi. Dalam hal ini materi bahasa inggris yang kami ajarkan adalah vocabulary (kosa kata) dasar dan pengenalan dasar saja karena sebagian besar santri TPQ adalah siswa usia sekolah dasar (SD).

Tentunya materi pembelajaran bahasa Inggris yang diberikan perlu dipersiapkan secara intensif dan sesuai dengan kebutuhan dan usia santri. Selain itu, kami juga memberikan pembinaan dan pelatihan bahasa Inggris dasar kepada tenaga pengajar TPQ (ustadz dan ustadzah) agar nantinya mereka juga bisa mengajar bahasa inggris yang telah terintegrasi dengan pembelajaran TPQ, sehingga program ini bisa berkelanjutan.

Tujuan dari kegiatan Pengabdian Kepada Masyarakat (PKM) ini adalah agar para santri TPQ Al-mataab desa tembokrejo memiliki kemampuan dasar dan mengenal kosa kata dasar bahasa Inggris, meningkatkan semangat dan menumbuhkan minat anak - anak TPQ untuk terus belajar bahasa Inggris, serta memberikan semangat kepada guru TPQ (ustadz dan ustadzah) untuk selalu motivasi dan mampu mengenalkan dan mengajarkan bahasa Inggris dasar kepada santrinya.

\section{METODE PELAKSANAAN}

Ada banyak metode dan teknik dalam mengajar bahasa Inggris yang atraktif, asyik, dan menarik untuk anak usia sekolah dasar (English for young learners). Anak - anak yang berusia antara 5 sampai 12 tahun bisa dinyatakan sebagai Young Learners (Rixon, 1999). Penggunaan metode yang menyenangkan akan membuat siswa tertarik sehingga dapat menangkap dan memahami materi dengan lebih maksimal. Dalam memberikan pelatihan dasar bahasa Inggris di TPQ, kami akan menggunakan beberapa metode diantaranya:

a. Drilling

$$
\text { Menurut Astuningtias \& }
$$

Appulembang (2017) metode drill merupakan teknik mengajar yang dilakukan dengan memberikan kegiatan dan latihan secara berulang - ulang sehingga siswa mampu memahami proses dan tahap - tahap pembelajaran berdasarkan kebiasaan - kebiasaan yang ditanamkan terhadap siswa. Metode ini cocok untuk anak usia sekolah dasar dalam pengajaran kosa kata karena kosa kata yang disebutkan berulang kali, sering latihan pelafalan maka siswa bisa melafalkan kosa kata tersebut hingga benar pengucapannya, mudah menyerap dan mengingat hal - hal yang telah mereka pelajari karena diulang berkali - kali. Metode drill sangat bermanfaat bagi siswa karena mereka diberikan wawasan dan pengetahuan secara bertahap, latihan dan pengulangan membuat materi yang diberikan kepada siswa melekat dalam memori otaknya, selain itu metode drill membuat siswa lebih mudah memahami materi dan membuat mereka lebih aktif dalam proses pembelajaran (Susilowati, Santoso \& Hamidi, 2013). 
DOI: https://doi.org/10.21009/sarwahita.152.02

P-ISSN: 0216-7484

E-ISSN: 2597-8926

\section{b. Flashcard}

Flashcard adalah media kartu yang didalamnya terdapat gambar atau foto dan tertulis keterangan tentang gambar tersebut pada bagian belakang kartu (Hotimah, 2010). Flashcard sebagai media visual dapat menstimulasi memori anak dan sangat efektif dalam pengajaran vocabulary (kosa kata) dasar bahasa inggris karena dinilai praktis dan dapat menarik perhatian siswa. Metode ini juga sangat menyenangkan dan mampu merangsang pikiran dan minat siswa dalam proses belajar mengajar.

c. Lagu (song)

Lagu adalah sebuah musik yang memiliki lirik dan merupakan ekspresi jiwa seseorang yang dituangkan dalam bentuk nada yang mengandung ritme dan harmoni yang dinyanyikan oleh seseorang. Lagu bisa digunakan untuk mengajarkan kosa kata kepada siswa karena lagu dapat membuat siswa senang dan rileks. Rokhmah, Suryandari, \& Wahyudi (2014) mengungkapkan bahwa dengan bernyanyi mampu menambah kosa kata siswa, merangsang ingatan dan daya pikir siswa, menghilangkan stress dan membuat pikiran siswa lebih fresh dan santai. Lagu mampu meningkatkan proses penguasaan bahasa secara tidak sadar karena lagu bias memberikan kesenangan dan mengusir kebosanan, serta membuat anak lebih cepat mengenal dan menghafal kosa kata.

Prosedur penerapan bahasa Inggris yang terintegrasi dengan pembelajaran TPQ dilakukan melalui berbagai tahapan, diantaranya:

1. Persiapan meliputi sosialisasi program kepada pimpinan TPQ, mendata santri sesuai kelasnya, dan menyiapkan materi pelatihan dasar untuk santri

2. Melakukan pre test untuk mengetahui kemampuan awal bahasa inggris santri. 
DOI: https://doi.org/10.21009/sarwahita.152.02

P-ISSN: 0216-7484

E-ISSN: 2597-8926

Tabel 1. Jadwal Kelas A

\begin{tabular}{|c|c|c|c|}
\hline No & Tanggal & Materi & Tenaga Pengajar \\
\hline 1 & $29 / 09 / 2018$ & Pre test & M. Nashir, M.Pd \\
\hline 2 & $06 / 10 / 2018$ & Number & $\begin{array}{l}\text { Roudlotun NL, M.Pd } \\
\text { Mega Indriyani Putri }\end{array}$ \\
\hline 3 & $13 / 10 / 2018$ & Alphabet & $\begin{array}{l}\text { M. Nashir, M.Pd } \\
\text { Triska Setya Putri }\end{array}$ \\
\hline 4 & $20 / 10 / 2018$ & Color & $\begin{array}{l}\text { Roudlotun NL, M.Pd } \\
\text { Mega Indriyani Putri }\end{array}$ \\
\hline 5 & $27 / 10 / 2018$ & Things in the classroom & $\begin{array}{l}\text { M. Nashir, M.Pd } \\
\text { Mega Indriyani Putri }\end{array}$ \\
\hline 6 & $3 / 11 / 2018$ & Review Previous materials & $\begin{array}{l}\text { Roudlotun NL, M.Pd } \\
\text { Triska Setya Putri }\end{array}$ \\
\hline 7 & $10 / 11 / 2018$ & Fruits & $\begin{array}{l}\text { M. Nashir, M.Pd } \\
\text { Mega Indriyani Putri }\end{array}$ \\
\hline 8 & $17 / 11 / 2018$ & Vegetables & $\begin{array}{l}\text { Roudlotun NL, M.Pd } \\
\text { Triska Setya Putri }\end{array}$ \\
\hline 9 & $24 / 11 / 2018$ & Animals & $\begin{array}{l}\text { M. Nashir, M.Pd } \\
\text { Triska Setya Putri }\end{array}$ \\
\hline 10 & $25 / 11 / 2018$ & Post Test & Roudlotun NL, M.Pd \\
\hline
\end{tabular}

Tabel 2. Jadwal Kelas B

\begin{tabular}{|c|c|c|c|}
\hline No & Tanggal & Materi & Tenaga Pengajar \\
\hline 1 & $30 / 09 / 2018$ & Pre test & Roudlotun NL, M.Pd \\
\hline 2 & $07 / 10 / 2018$ & Number & $\begin{array}{l}\text { M. Nashir, M.Pd } \\
\text { Triska Setya Putri }\end{array}$ \\
\hline 3 & $14 / 10 / 2018$ & Spelling & $\begin{array}{l}\text { Roudlotun NL, M.Pd } \\
\text { Mega Indriyani Putri }\end{array}$ \\
\hline 4 & $21 / 10 / 2018$ & Parts of Body & $\begin{array}{l}\text { M. Nashir, M.Pd } \\
\text { Mega Indriyani Putri }\end{array}$ \\
\hline 5 & $28 / 10 / 2018$ & My Family & $\begin{array}{l}\text { Roudlotun NL, M.Pd } \\
\text { Triska Setya Putri }\end{array}$ \\
\hline 6 & $04 / 11 / 2018$ & Review Previous materials & $\begin{array}{l}\text { M. Nashir, M.Pd } \\
\text { Mega Indriyani Putri }\end{array}$ \\
\hline 7 & $11 / 11 / 2018$ & Greeting and Leave Taking & $\begin{array}{l}\text { Roudlotun NL, M.Pd } \\
\text { Triska Setya Putri }\end{array}$ \\
\hline 8 & $18 / 11 / 2018$ & Introduction & $\begin{array}{l}\text { M. Nashir, M.Pd } \\
\text { Triska Setya Putri }\end{array}$ \\
\hline 9 & $24 / 11 / 2018$ & Practice Introducing Oneself & $\begin{array}{l}\text { Roudlotun NL, M.Pd } \\
\text { Mega Indriyani Putri }\end{array}$ \\
\hline 10 & $25 / 11 / 2018$ & Post Test & M. Nashir, M.Pd \\
\hline
\end{tabular}

Dalam kegiatan pendampingan para baru karena di sekolah mereka belum santri sangat antusias dan bersemangat mendapatkan pelajaran bahasa Inggris. dalam mengikuti kegiatan pembelajaran bahasa inggris. Sebagian besar dari mereka, Antusiasme siswa bisa dilihat dari potret kegiatan sebagi berikut: terutama kelas A ini merupakan hal yang 


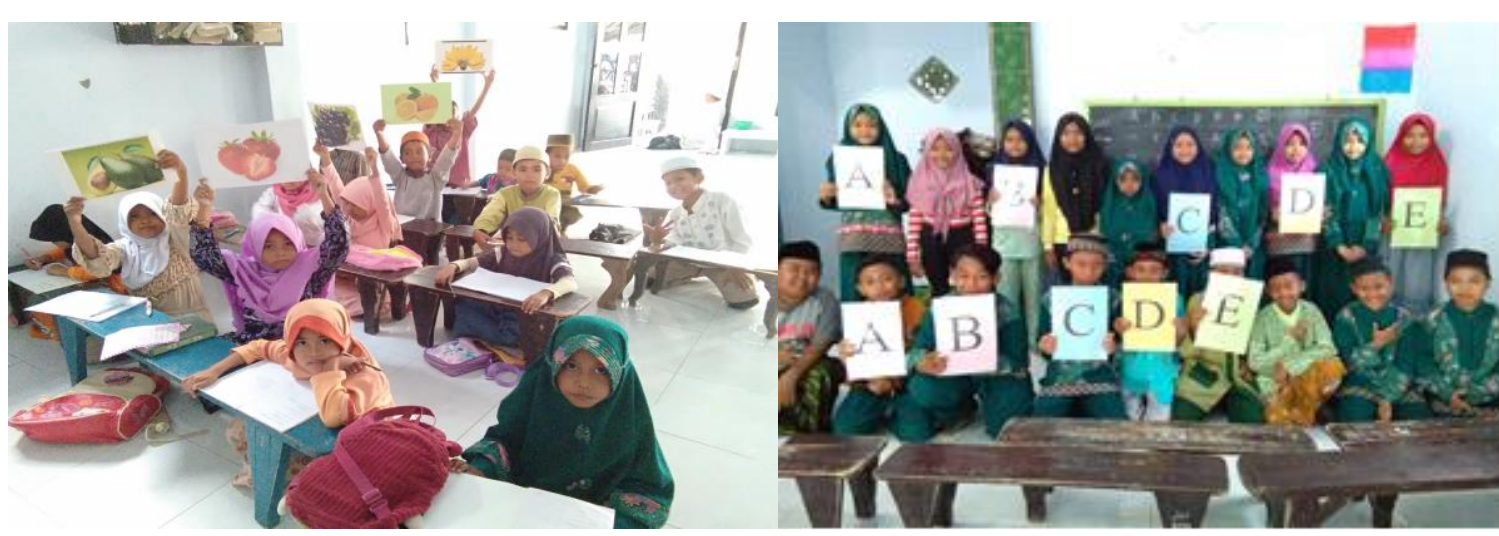

Gambar 1\&2. Santri belajar kosa kata tentang buah dan alfabet
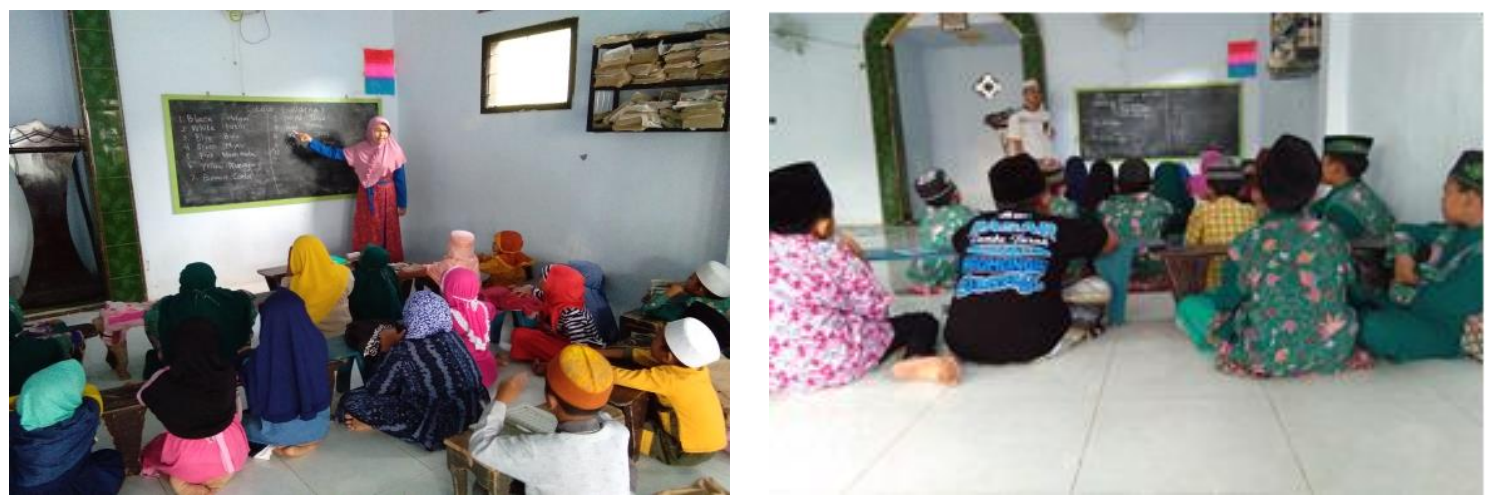

Gambar 3\&4. Santri antusias mengikuti kegiatan pembelajaran bahasa inggris

Selama kegiatan berlangsung tidak ada kendala yang berarti. Sedikit kendala dalam mengkondisikan kelas A sebelum pembelajaran untuk bisa menarik perhatian mereka karena usia mereka rata - rata masih 7-10 tahun jadi butuh tenaga ekstra untuk membuat mereka bisa focus ke materi yang diajarkan. Setelah kegiatan pendampingan dan pemberian materi kosa kata dasar selama 8 kali pertemuan, post test diberikan kepada siswa untuk mengetahui kemajuan dari kegiatan pengabdian masyarakat ini. Hasil post test kelas A menunjukkan rata - rata kelas 62.41 dan kelas B 71.6. Kedua kelas mengalami peningkatan nilai post test yang lebih tinggi daripada nilai pre tes.

\section{PENUTUP}

Pengintegrasian bahasa Inggris dalam kurikulum TPQ sangat mungkin dilakukan dan bagus diterapkan agar santri selain pandai mengaji, memahami ilmu agama juga mampu bersaing secara global di era sekarang ini. Diharapkan agar kegiatan pembelajaran bahasa Inggris ini terus berkelanjutan. Program kegiatan yang dilakukan berjalan dengan lancar sesuai dengan jadwal yang telah ditentukan. Respon ketua TPQ dan dewan pengajar ustad dan ustadzah juga bagus, serta antusiasme santri dalam pembelajaran bahasa inggris sangat baik. Dari kegiatan pendampingan dan pengajaran yang dilakukan, hasil menunjukkan bahwa penguasaan kosa kata bahasa Inggris santri mengalami peningkatan yang bisa dilihat dari perbandingan nilai pre test kelas A 43.89 meningkat ke 62.41 , begitu juga pada kelas B dari 61.4 menjadi 71.6. 
DOI: https://doi.org/10.21009/sarwahita.152.02

P-ISSN: 0216-7484

E-ISSN: 2597-8926

\section{DAFTAR PUSTAKA}

Astuningtias, K. I., \& Appulembang, O. D. 2017. Penerapan Metode Drill untuk Meningkatkan Hasil Belajar Kognitif Siswa Kelas IX Materi Statistika di SMP Kristen Rantepao. JOHME: Journal of Holistic Mathematics Education, 1 (1), $53-59$.

Crystal, D. 2003. English as a Global Language. New York: Cambridge University Press.

Hotimah, E. 2010. Penggunaan Media Flashcard dalam Meningkatkan Kemampuan Siswa pada Pembelajaran Kosakata Bahasa Inggris Kelas II MI Ar-Rochman Samarang Garut. Jurnal Pendidikan 04 (01).
Joesoef, S. 1992. Konsep Dasar Pendidikan Non Formal. Jakarta: Bumi Aksara Rixon, S. 1999. Young Learners of English: Some Research Perspectives. London: Longman

Rokhmah, K., Suryandari, K. C., \& Wahyudi. 2014. Penggunaan Metode Sing a Song dalam Upaya Peningkatan Motivasi dan Hasil Belajar Bahasa Inggris Siswa Kelas IV SDN Tegalsari. Kalam Cendekia 5 (1.1), 36-41.

Susilowati, E., Santoso, S., \& Hamidi, N. 2013. Penggunaan Metode Pembelajaran Drill Sebagai Upaya Meningkatkan Prestasi Belajar Akuntansi. Jurnal Pendidikan Ekonomi UNS 1(3), 1 - 10. 